\title{
Moving sociohydrology forward: a synthesis across studies
}

\author{
T. J. Troy ${ }^{1}$, M. Konar ${ }^{2}$, V. Srinivasan ${ }^{3}$, and S. Thompson ${ }^{4}$ \\ ${ }^{1}$ Department of Civil and Environmental Engineering, Lehigh University, STEPS 9A, 1 W. Packer Ave, Bethlehem, \\ PA 18015, USA \\ ${ }^{2}$ Department of Civil and Environmental Engineering, University of Illinois at Urbana-Champaign, 2525 Hydrosystems \\ Laboratory, 205 N. Mathews Ave, Urbana, IL 61801, USA \\ ${ }^{3}$ Ashoka Trust for Research in Ecology and the Environment, Royal Enclave Sriramapura, Jakkur Post, Bangalore 560064 , \\ Karnataka, India \\ ${ }^{4}$ Department of Civil and Environmental Engineering, University of California, Berkeley, 661 Davis Hall, Berkeley, \\ CA 94720, USA
}

Correspondence to: T. J. Troy (tara.troy@lehigh.edu)

Received: 2 March 2015 - Published in Hydrol. Earth Syst. Sci. Discuss.: 25 March 2015

Revised: 15 July 2015 - Accepted: 28 July 2015 - Published: 25 August 2015

\begin{abstract}
Sociohydrology is the study of coupled humanwater systems, building on the premise that water and human systems co-evolve: the state of the water system feeds back onto the human system, and vice versa, a situation denoted as "two-way coupling". A recent special issue in HESS/ESD, "Predictions under change: water, earth, and biota in the Anthropocene", includes a number of sociohydrologic publications that allow for a survey of the current state of understanding of sociohydrology and the dynamics and feedbacks that couple water and human systems together, of the research methodologies being employed to date, and of the normative and ethical issues raised by the study of sociohydrologic systems. Although sociohydrology is concerned with coupled human-water systems, the feedback may be filtered by a connection through natural or social systems, for example, the health of a fishery or through the global food trade, and therefore it may not always be possible to treat the human-water system in isolation. As part of a larger complex system, sociohydrology can draw on tools developed in the social-ecological and complex systems literature to further our sociohydrologic knowledge, and this is identified as a ripe area of future research.
\end{abstract}

\section{Introduction}

Many of the major improvements in hydrology in the past decades have been grounded in the understanding of natural systems. The significant modification of the water cycle by human activity has primarily been treated as an external perturbation to such natural systems. However, externalizing the dependencies between human action and the availability, quality and dynamics of water clearly poses limitations to making predictions about water within the Anthropocene (Thompson et al., 2013). To address these limitations, a new generation of studies now focus on sociohydrology, which aims to understand the dynamics and co-evolution of coupled human-water systems (Sivapalan et al., 2012). Within sociohydrology, humans and their activities are considered as part of the water cycle, rather than as an external driver (Sivapalan et al., 2012). The interplay of cause and effect between human activity and hydrologic dynamics therefore becomes a primary topic of research interest. Improved understanding of the relationships between human decision-making (as it pertains to water systems) and the condition of the water system itself may lead to better prediction, and thus management, of water systems.

This joint Hydrology and Earth System Sciences/Earth System Dynamics special issue, "Predictions under change: water, earth, and biota in the Anthropocene", contains a wide range of studies, from the impact of climate change on water resources to large-sample hydrology. In particular, it contains 
a number of sociohydrology-focused studies, which, along with other recent publications, can be taken to represent the current state of this emerging field. Here we take the opportunity to use these sociohydrologic studies as a basis for a synthesis of the emerging questions and challenges that the research community faces as it grapples with the nature and practice of sociohydrology. Three major themes emerge for further consideration: (i) the state of our understanding of the coupling between human society and hydrology, (ii) the strengths and new opportunities in the suite of research approaches used within sociohydrology, and (iii) the normative and ethical questions that arise in the context of sociohydrologic research, which are often neglected in research on the hydrology of natural systems.

\section{State of understanding of sociohydrology: water-society dynamics}

Sociohydrology is conditioned on the existence of connections, coupling and feedback between elements of the water cycle and the society being studied. In this sense, sociohydrology isolates a suite of specific processes from within a broader social-ecological system (SES) comprising the resources, users, and governance subsystems relevant to a given society (Ostrom, 2009). An SES is a type of complex system, which can be differentiated from other dynamical systems by the presence of multiple interacting components, local connections and nonlinear relationships between the components (Levin, 1998; Solé and Bascompte, 2006). As a consequence of these features, complex systems (and SES) can display a wide variety of dynamical behaviors, including thresholds, self-organization, chaos, multi-stability, and path dependence (i.e., a dependence on history). Complex systems pose major challenges to modeling, inference and analysis in general. Sociohydrology therefore faces the challenge of identifying the pathways of influence between water and social responses within a broader and more complex web of cause-and-effect represented by a society and its dependence on and regulation of the use of natural resources.

Isolating the sociohydrologic components of an SES is non-trivial since water resources affect many of the other resources within the SES. Thus, a sociohydrologic relationship may arise directly - for example, a direct relationship between reduced well-being and water scarcity (Srinivasan, 2015) - or indirectly, for example, a relationship between economic output from a fishery and water quality. Changes in flow regimes can affect fish species richness (Yoshikawa et al., 2014), and regions dependent on fishing may become sensitive to hydrologic change through the impact on fish rather than water quantity. Fundamentally, the presence of multiple pathways for coupling between water and society, and the potential for these pathways to occur indirectly and to be influenced by other components of the system, suggests the study of sociohydrology is prototypical of complex sys- tems science. Typical of complex systems, sociohydrologic systems are likely to exhibit nonlinear dynamics and thresholds (Liu et al., 2007) with scale mismatches between the two systems (Cumming et al., 2006). For example, there can be a spatial scale mismatch between small farmers' perception of the impacts of their irrigation activities and the overall large-scale hydrologic change in the region, where the farmers' impacts might be experienced downstream. More specific examples of these effects as revealed by the studies presented in the special issue are outlined below. Methodologically, framing sociohydrology as an SES suggests that techniques used in the SES and coupled natural-human systems research fields have the potential to advance sociohydrology (see Sect. 3).

In an idealized sense, sociohydrology aims to understand the co-evolution of human and water systems and thus posits that a two-way coupling exists between these systems. Individual case studies, however, exhibit tremendous variability in terms of the strength of the relationships between water and society, in the pertinent response timescales, and in oneway vs. two-way coupling. Figure 1 conceptually illustrates a suite of coupling structures. In some cases, the coupling is direct; in others, it is indirect and is mediated by other systems, including institutions, economic drivers, or infrastructure (Fig. 1b and c). In others, an element of the coupling may be dynamic and the feedback can only occur under certain conditions (Fig. 1d). Table 1 provides a summary of feedbacks in the studies in this special issue. In systems with slow changes, two-way coupling may only become evident when an observation window is long enough to reveal the changes in either system and when the influence of water on society, or vice versa, is sufficiently direct that it can be isolated as a driver of change. Because observational periods are often constrained and because sociohydrologic dynamics are nested in a broader SES and can often be indirect, many studies are able to explore only the one-way influence of water $\rightarrow$ humans or humans $\rightarrow$ water. It is also possible that in some cases one-way feedbacks are all that exist.

The spatial scale at which a sociohydrologic system is conceptualized can also influence the way that coupling emerges. For example, national food prices can influence the number of acres planted for agricultural production, with flowon effects on irrigation water demands and streamflow availability. Energy extraction technology and market dynamics have made hydraulic fracking much more attractive in many regions, which may then impact the local sociohydrologic system through water requirements and pollution concerns. While regional or global models can internalize these dynamics, smaller-scale models may be forced to treat them as external, and thus one-way, drivers of sociohydrology.

Furthermore, several examples where human and water systems are tightly coupled, but only develop on an intermittent basis, can be found. Kumar (2011) call this intermittency "dynamic connectivity", which can either arise along a continuum or emerge as a threshold behavior. Such threshold 
Table 1. Site-specific coupled human-water models.

\begin{tabular}{|c|c|c|c|c|}
\hline Citation & Feedbacks & Description of feedbacks & Exogenous drivers & Type of model \\
\hline \multirow[t]{2}{*}{ Chang et al. (2014) } & Water quality $\rightarrow$ humans & $\begin{array}{l}\text { Scientific knowledge and human perceptions about local } \\
\text { water quality influence policy }\end{array}$ & $\begin{array}{l}\text { Climate, urbaniza- } \\
\text { tion, demography }\end{array}$ & Statistical \\
\hline & Humans $\rightarrow$ water quality & $\begin{array}{l}\text { Governance in turn affects local water quality over time in } \\
\text { urban areas through the type and extent of monitoring, etc. }\end{array}$ & & \\
\hline \multirow[t]{2}{*}{$\begin{array}{l}\text { Di Baldassarre et } \\
\text { al. (2013b) }\end{array}$} & Humans $\rightarrow$ hydrology & $\begin{array}{l}\text { Flood damage depends on distance of settlement from river, } \\
\text { settlement size, and height of levees }\end{array}$ & Technology, culture & $\begin{array}{l}\text { Toy: assumptions } \\
\text { from literature }\end{array}$ \\
\hline & Hydrology $\rightarrow$ humans & $\begin{array}{l}\text { Economic activity (which grows/shrinks slowly) abruptly } \\
\text { shrinks after major floods. } \\
\text { Human decisions on settlement and investment in levees de- } \\
\text { pend on the memory of the last flood and economic and tech- } \\
\text { nological factors. }\end{array}$ & & \\
\hline \multirow[t]{3}{*}{$\begin{array}{l}\text { Elshafei } \\
\text { al. (2014) }\end{array}$} & $\begin{array}{l}\text { Hydrology } \rightarrow \text { ecosystem } \\
\text { services }\end{array}$ & $\begin{array}{l}\text { Ecosystem services are a function of water quality, environ- } \\
\text { mental flows and vegetation. }\end{array}$ & $\begin{array}{l}\text { Climate, political, } \\
\text { cultural and } \\
\text { socio-economic } \\
\text { factors }\end{array}$ & $\begin{array}{l}\text { Toy: assumptions } \\
\text { from the literature }\end{array}$ \\
\hline & Ecosystem services $\rightarrow$ humans & $\begin{array}{l}\text { Loss of ecosystem services, along with external factors like } \\
\text { politics and economic growth, drive community sensitivity } \\
\text { to the environment. }\end{array}$ & & \\
\hline & Humans $\rightarrow$ hydrology & $\begin{array}{l}\text { Humans abstract water for productive uses. Communities } \\
\text { also act to restore water systems if the level of sensitivity } \\
\text { to the environment exceeds productive demands for water. }\end{array}$ & & \\
\hline \multirow[t]{2}{*}{$\begin{array}{l}\text { O’Connell and } \\
\text { O'Donnell (2014) }\end{array}$} & Hydrology $\rightarrow$ humans & $\begin{array}{l}\text { Damage function as a function of flood magnitude and level } \\
\text { of protection. }\end{array}$ & $\begin{array}{l}\text { Climate change, } \\
\text { flood protection }\end{array}$ & Statistical \\
\hline & Humans $\rightarrow$ hydrology & $\begin{array}{l}\text { Inclusion of an } \mathrm{ABM} \text { to model flood protection decisions } \\
\text { discussed but not implemented. }\end{array}$ & & \\
\hline \multirow[t]{2}{*}{ Srinivasan (2015) } & Humans $\rightarrow$ hydrology & $\begin{array}{l}\text { People with wells extract groundwater depending on avail- } \\
\text { ability of water from other sources. Investment in reservoir } \\
\text { storage depends on the ability of the water utility to make } \\
\text { investments. }\end{array}$ & $\begin{array}{l}\text { Economic, popula- } \\
\text { tion growth }\end{array}$ & $\begin{array}{l}\text { Process-based using } \\
\text { site-specific data }\end{array}$ \\
\hline & Hydrology $\rightarrow$ humans & $\begin{array}{l}\text { When the water table drops, peoples' wells go dry and they } \\
\text { are forced to buy water from other sources. } \\
\text { Investment in wells increases/decreases depending on relia- } \\
\text { bility of piped water. }\end{array}$ & & \\
\hline Zhang et al. (2014) & Humans $\rightarrow$ hydrology & $\begin{array}{l}\text { Land use change, irrigation expansion and climate variability } \\
\text { influence the flows of green and blue water. }\end{array}$ & $\begin{array}{l}\text { Land use change, ir- } \\
\text { rigation expansion, } \\
\text { climate }\end{array}$ & Process-based \\
\hline $\begin{array}{l}\text { Yoshikawa } \\
\text { al. (2014) }\end{array}$ & Hydrology $\rightarrow$ ecosystems & $\begin{array}{l}\text { Fish species richness (FSR) depends on flow characteristics } \\
\text { of rivers, which are expected to alter with climate change. }\end{array}$ & Climate change & Statistical \\
\hline Zeng et al. (2014) & Humans $\rightarrow$ hydrology & Land use change accompanied by irrigation expansion & $\begin{array}{l}\text { Climate, land use } \\
\text { patterns }\end{array}$ & $\begin{array}{l}\text { Process-based using } \\
\text { site-specific data }\end{array}$ \\
\hline
\end{tabular}

dynamics clearly arise for human-water interactions when considering the strong coupling that emerges during extreme events (such as flooding or extreme drought), while water availability during "normal" conditions may have limited influence on a society. Continuum examples of dynamic connectivity include the long-term emergence of water crises as a combination of environmental constraints, infrastructure development and changing demand. The challenge, of course, is predicting when such crises - and thus tight sociohydrologic coupling - will arise.

\subsection{Feedbacks within a sociohydrologic system}

Understanding the feedbacks within sociohydrologic systems can be furthered by exploring the range of coupling structures found in the special issue, including onedirectional influence, two-way coupling, and dynamic connectivity.

\subsubsection{One-directional influence}

The majority of the papers in the special issue focus on oneway influences, and many studies remain within the "natural systems paradigm" in which human action is externalized 
A
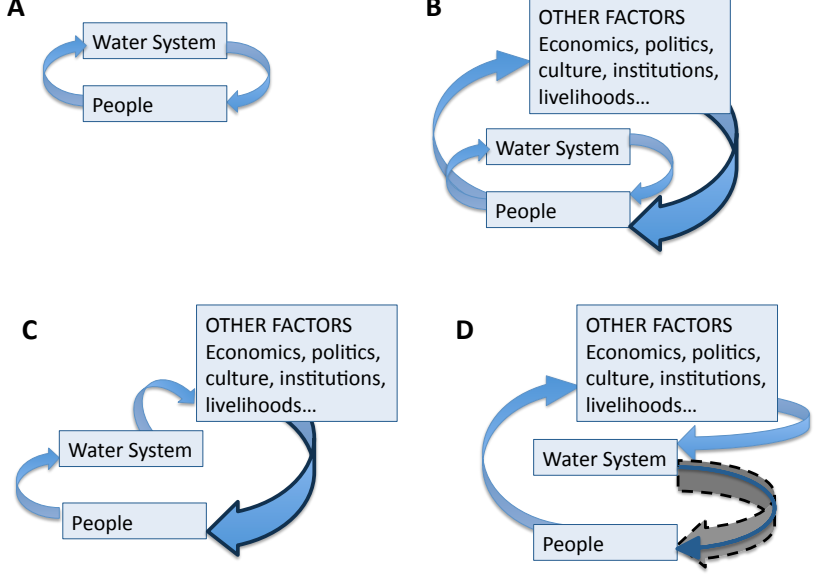

Figure 1. Multiple forms of coupling between a water system and a target study population of people can arise. In the simplest case, (a), both the water system and the target population are tightly and directly coupled to each other - as might arise for subsistence farmers in a water-limited system. In many other cases, (b), the target population is not only affected by changes in the water system, but also by a suite of other issues, meaning that changes to the target population in response to water issues occur slowly. This is complicated, (c), when the effects of water on the target population are indirect and filtered through other institutions, spatial scales and social or environmental systems, meaning that isolating the effects of water from the whole complex system is difficult. Because of the time, spatial and institutional separations in scale between water and human populations, tight coupling between water systems and human responses often arises only intermittently, (d), as a "dynamic connectivity" (sensu Kumar, 2011), often in response to a crisis (e.g., critical water scarcity or severe flooding).

and treated as a perturbation to a natural hydrologic regime. For example, several studies considered the effects of land use change altering the hydrologic regime, through increased irrigation in the Heihe River in China (Zhang et al., 2014), alterations to the water cycle through tile drainage (Yaeger and Sivapalan, 2013), irrigation from groundwater in the midwestern US (Zeng and Cai, 2014), and deforestation in eastern Mexico (Muñoz-Villers and McDonnell, 2013). The oneway nature of influence in these studies possibly results from a timescale separation between the rapid timescales of human intervention in the water cycle and the longer timescales on which these interventions alter agricultural productivity.

The spatial scale separation challenge also results in some sociohydrologic studies in the special issue focusing primarily on one-way influences. For example, Konar et al. (2013) examined how changing spatial patterns of crop yield would affect the water footprint of trade in the coming decades, and O'Bannon et al. (2014) examined how agricultural trade concentrates water pollution in only a handful of countries. The separation in spatial scale between international trade and local farmer decision-making highlights the need to understand the interactions and effects of human actions at differ- ent scales, which remains a challenge in the fields of microand macro-economics, and the scale separation may make it inevitable that only one-way interactions can be evaluated. However, it may be possible to link processes across scales to reveal the full suite of feedbacks if we reconcile "top-down" (i.e., relatively large spatial scale) and "bottom-up" (i.e., relatively small spatial scale) human processes. If the full range of processes across scales is understood, it may be possible to move from studying only one-way interactions to two-way couplings at different scales.

\subsubsection{Two-directional coupling}

Several studies explored two-way coupling in specific regions: in Chennai, India (Srinivasan, 2015); Portland, Oregon, in the US (Chang et al., 2014); the Murrumbidgee in eastern Australia (Elshafei et al., 2014; Kandasamy et al., 2014; van Emmerik et al., 2014); the Toolibin catchment in western Australia (Elshafei et al., 2014); and Saskatchewan in Canada (Gober and Wheater, 2014). In the majority of these studies, the focus was on water scarcity generated primarily by human water demands. Other studies focused on the human-water systems coupling in the context of flooding (Di Baldassarre et al., 2013b; O'Connell and O'Donnell, 2014). Many of these examples conform to the notion of a sociohydrologic system that is embedded in a larger SES, resulting in an indirect coupling between water and society (Fig. 1c). Identifying the complete suite of interactions that constitute the pathways of influence between changes in water and changes in a social metric remains a significant challenge in these studies. For example, Chang et al. (2014) explored the feedback between water quality and house prices, and land use policy and water quality. Although there is likely to be a relationship between home prices and land use policy as well, which would allow the feedback loop to be "closed", this relationship was not identified by the researchers, making it difficult to determine the complete set of relationships between land use, house prices and water quality.

Two-way coupling is more evident in studies that outline the history of human-water systems, illustrating how the systems changed together over time. A common inference drawn from these studies is that two-way coupling between the human and water systems has tended to strengthen over time as human water demands grew in relation to the available water supply (analogous to the nonlinear dynamics situation in which a forward process becomes progressively inhibited by a strengthening negative feedback). For example, Pande and Ertsen (2014) found that water scarcity triggered complex cooperative agreements in two ancient societies. In the Tarim River in China, the arid hydroclimatology of the basin initially limited human settlement. People could only settle along oases and the river; the mean annual precipitation of $50-100 \mathrm{~mm} \mathrm{yr}^{-1}$ was insufficient to support human development elsewhere in the basin. During the 19th 
and 20th centuries, irrigated agriculture and its associated infrastructure allowed human activities to affect the hydrologic regime, with the infrastructure releasing the water resource constraints previously placed on human settlement. Growing population and water demands eventually outpaced the water availability, leading to environmental degradation and a re-prioritization of water resources (Liu et al., 2014), in a situation where water is strongly managed by people and where water limitations strongly limit human activity in the region. Other basins displayed similar transitions. In the Murrumbidgee in Australia during the first half of the 20th century, human water appropriation for irrigation was the dominant dynamic. Only when water stress and environmental degradation reached an unacceptable threshold were legislative and social norms applied to modulate water use, resulting in a tightly coupled sociohydrologic system (Kandasamy et al., 2014). Notably, the effect of changing hydrology on social systems in these studies emerged on decadal to century timescales (Kandasamy et al., 2014), and frequently has only manifested in social change in recent years. Typically, these social changes occurred in response to some form of heightened social "sensitivity" to the condition of the water system. This sensitivity takes the form of a normative shift towards increased societal valuation of the environment and the water system, typically in response to the experience of degradation or scarcity. In New Mexico, traditional communities have adapted to hydrologic variability for centuries while simultaneously affecting the hydrologic cycle through irrigation, and this coupling has led to a resilient system (Fernald et al., 2015).

\subsubsection{Dynamic connectivity}

In many of the papers studying two-way coupling, the strength and, in some cases, the existence of the feedbacks between human and water systems changed with time. This dynamic connectivity is an important consideration when studying these systems with two-way coupling, as it implies that if one were to study the feedbacks between different system components as static in time, important transitions and evolutions in the coupled human-water system would be missed. Gober and Wheater (2014) showed that hydrology is continually modified by human activity, with these modifications increasing as populations grow and water resources become fully allocated. Not until drought revealed the extent of the water scarcity crisis was a feedback to decisionmaking about water activated. Under drought crisis conditions, decision-makers were willing to explore changes to the infrastructure and governance used to manage the water resources. Similarly, Di Baldassarre et al. (2013a) showed that flooding significantly reduced the floodplain population density for some years afterwards; however, with the fading memory of the flood, population growth in the floodplain resumed. In this case, there was an immediate feedback (population decline) whose importance diminished over time. O'Connell and O'Donnell (2014) indirectly examined the effects of this intermittency in floodplains, exploring how flood-rich (when water $\rightarrow$ society feedbacks are stronger) and flood-poor (when these feedbacks are eroded) periods might affect the decisions made about flood management. Intermittency in coupling appears to arise when thresholds are crossed: thresholds related to changing community values about the environment (Elshafei et al., 2014), water scarcity (Gober and Wheater, 2014), infrastructure development (Liu et al., 2014), or acute environmental damage (Di Baldassarre et al., 2013a). This intermittency could be viewed as another manifestation of social sensitivity to the state of the water system - but in this case induced by the experience of extreme, and often non-stationary, events, decreasing in strength and importance over time (Di Baldassarre et al., 2013b).

Ribeiro Neto et al. (2014) laid out a hypothesized sequence of coupled human-water system development. First human water demands exceed the locally available water supply, leading to infrastructure development to stabilize and/or enhance the local supply. Eventually, the water demands grow beyond the infrastructure capacity, leading to new infrastructure that captures the non-local supplies. They point out that this leads to sociohydrologic system transitions: in their study, this involved a reconfiguration of spatial and sector water demands in response to water availability. Their hypothesized sequence allows for dynamic connectivity, with the system switching between one-way and two-way feedbacks, depending on the balance between supply and demand. The rate at which sensitivity develops, and the extent to which social uses of water respond to this sensitivity, is strongly socially mediated.

\subsection{What comprises a sociohydrologic system?}

The definition of sociohydrology as the study of a two-way coupling between human and water systems is clearly challenged by the observation that sociohydrologic systems are embedded in a broader SES, subject to time and spatial scale separations and to intermittency in the very existence of a two-way coupling. With this background, a case can be made that studies considering exogenous effects of people on hydrologic systems, without a consideration of feedback mechanisms, should form part of the scope of sociohydrologic research - and indeed, important insights into the nature of human-imposed change on water systems can be derived from such studies. Clearly, however, sociohydrology cannot be limited to studies within such a "natural systems" paradigm.

It would be equally problematic, however, to confine sociohydrologic studies to consideration of situations where consistent, strong two-way human-water feedbacks arise. Based on the studies in the special issue, we hypothesize that such "tight coupling" is a special case, arising in systems with simple water and social infrastructure - such as 
irrigated subsistence agriculture in a water-limited region or in situations where some form of water crisis (or other threshold) is reached. Below such a threshold, the coupling in most sociohydrologic systems appears to be strongly oneway in terms of human influence on hydrology, with little or weak coupling from water to human systems. Thresholds may be stochastically determined - e.g., by drought (Gober and Wheater, 2014) or by flooding (Di Baldassarre et al., 2013b). The exception may be in extremely arid basins, where human development is constrained by available water if there is a lack of infrastructure (water to human rather than the opposite), which was seen in the Tarim River (Liu et al., 2014). Moreover, it is not inevitable that thresholds exist - they are presumably a function of the socio-ecologic system that is being considered. For example, the Aral Sea retreat that began under the Soviet Union and has since continued imposes significant costs on the communities and environments near the former shoreline, yet this environmental catastrophe has not been sufficient to alter patterns of water use (Micklin, 2007). The fact that no feedback on the water use mechanisms has occurred potentially reflects the relative political weight given to the environment and local population versus the maintenance of upstream irrigated agriculture. Social responses to hydrologic crises may be significantly delayed (Kandasamy et al., 2014), and different societies and political systems may be more sensitive to certain hydrologic impacts than others. Yet the lack of an evident two-way feedback mechanism should not exclude such important cases from being considered within the umbrella of sociohydrology. Instead, the framework of viewing sociohydrology as a subset of a broader socio-ecologic system, a complex system in which multiple pathways of influence link hydrological and social dynamics, offers a conceptual model that can encompass many different forms, and directions, of influence between human and water systems.

\section{Research methodologies and data needs}

The sociohydrologic studies discussed above have used a range of research methodologies, including historical analysis, simplified systems of differential equations, and statistical-empirical analyses. Based on these studies, some data and methodological challenges arise. If one views sociohydrology as a field of study that focuses on particular components of a complex system, then complex systems science has developed empirical, modeling and analytical techniques that apply to complex systems and that can be utilized in sociohydrologic research. Some of these approaches are already being applied by researchers in sociohydrology, while other methodologies represent new opportunities for discovery. More fundamentally, however, sociohydrology poses significant challenges for data collection and data generation. Long-term data sets of both social and hydrological data can be difficult to find, but alternative sources and approaches may fill this gap.

\subsection{Sociohydrologic data}

Detailed hydrologic data have a finite history, with the majority of the instrumented hydrological record having been collected in the past 100 years. Longer-term analyses typically require the use of proxy data, whether physical (e.g., sedimentology) or historical (e.g., tax records, oral histories of flooding). Social data sets are broader in their potential scope, and while they may extend for long periods of time, data availability is likely to place a strong constraint on the kinds of sociohydrologic questions that can be addressed post hoc. Given the observation that evidence of social changes in response to changing water dynamics typically emerges over long timescales or in response to specific episodes, long-term records describing water and people's interactions with water are likely to be essential.

To date, two different approaches have been used to address data availability. The first of these is an attempt to assemble a historical archive of physical and human data over sufficiently long timescales to reveal key dynamics (Dermody et al., 2014). Physically, there is a broad suite of proxy data that can be used to extend physical records into historical or even deep time. Even where the data are not specifically hydrologic, a combination of paleoclimatological methods and hydrologic modeling can provide a plausible representation of historical flow regimes and hydrologic behavior (French et al., 2012).

Data regarding social dynamics may need to be pieced together from multiple sources, such as narrative information, numerical records (crop planting dates, flood levels), pictorial information, or archaeological information (flood levels and excavations) (Brádzil and Kundzewicz, 2006; Brádzil et al., 2006, 2012). Parker (2008) refers to the development of these multi-sourced data sets as the creation of a "human archive" for the historical period. Robust and reliable techniques to generate physical and human historical archives represent an important area of methodological development in sociohydrology: for example, Ertsen et al. (2014) detail several different ways to collect data from archaeological data on irrigation systems, including looking at the sedimentation in the canals and climate reconstruction with tree-ring data. Similarly, Zlinszky and Timár (2013) laid out a methodology for the analysis of historical maps that specifically addresses the correction of errors resulting from cartography in the pre-photographic era. Even when detailed data are unavailable, historical studies can illuminate broad sensitivities and correlations between society and hydrology. For example, social and economic contraction, simplification, and periods of destruction in the Kingdom of Angkor (in presentday Cambodia) coincided with droughts of sufficient severity and duration to deplete the kingdom's water storage and supply mechanisms (Buckley et al., 2010), while worldwide 
incidents of rebellion in the 17th century were often coincident with extreme weather phenomena (Parker, 2008). The diversity of potential approaches and data sources suggests that methodological questions in the compilation of sociohydrologic data sets will be a rich and challenging component of the field.

An alternative approach that circumvents the challenges in assembling a long data record is to undertake comparative studies over relatively short time periods but across multiple sites. In the absence of controlled experiments, comparative studies provide opportunities to generate insights based on systematic differences arising in different locations and watersheds. Comparative studies can be primarily qualitative, investigating a limited number of sites in great detail, with the goal of generating conceptual understanding. In this mode, Scott et al. (2014) compared three agricultural catchments to understand the relationship between irrigation efficiency improvements and basin resilience. Across three cases, they find that expanding irrigation efficiency without limits on use or irrigated area may increase production, but it could worsen resilience to water scarcity. Similarly, Wescoat Jr. (2013) presented a comparative analysis of the "duty of water" concept, a standard governing application of irrigation water. Although the duty of water concept was applied in both British India and the United States in order to maximize the utilization of irrigation water, its use evolved in opposite directions, because of the different social conditions prevailing in each nation.

An alternative comparative methodology leverages the greater statistical power associated with a large number of data points as a technique to overcome the inherent heterogeneity of catchments. Comparative hydrology was initiated in the late 1980s (Falkenmark and Chapman, 1989). For sociohydrologic analysis, this approach is extended to incorporate social variables in addition to environmental and climatic drivers, ideally exploring behavior across important gradients in social factors. Wutich et al. (2014) compared cross-cultural water management choices across gradients of water scarcity and per capita income. They found that people in less developed sites had small-scale, decentralized, community-based water management solutions, while people in more developed sites favored large-scale, centralized, infrastructure and regulatory solutions. A conceptual framework for undertaking such comparative studies was presented in Thompson et al. (2013), although the challenges inherent in this approach have also been highlighted, such as data availability and sharing protocols (Gupta et al., 2014). Comparative studies may be most effective where they can be used to test specific hypotheses. For example, the hypothesis proposed for the Murrumbidgee of irrigation moving upstream and then back downstream due to development and then a re-prioritizing of water usage (Kandasamy et al., 2014; Sivapalan et al., 2012) could be explored across many locations to evaluate whether it is an evolutionary pattern specific to the case study or whether it is illustrative of a broader phenomenon arising as a consequence of the intersection of development pathways, water usage priorities, and environmental attitudes during the past century. While potentially powerful, comparative studies are data intensive, and the generation of appropriately curated, quality assured and meaningful social data sets that could be included in such studies remains a major challenge to widespread use of such approaches.

\subsection{Causal inference}

If the data availability and reliability challenges associated with sociohydrology can be overcome, a broad range of techniques are available to analyze the data. Of particular interest are the tools available to recognize the complex-systems nature of the problem. Complex system studies have developed a very broad toolkit for data analysis, including techniques to evaluate causal relationships (e.g., information theory, synchronicity and time delays, and entropy-based measures; Thompson et al., 2013), to reconstruct the underlying complex system based on time-series measures (e.g., attractor reconstruction, recurrence metrics, etc.; Shalizi, 2006), and even to analyze time series based on object-oriented occurrences of "patterns" in the time series (an approach that may be suitable to use when quantitative data are unavailable) (Das et al., 1998). This is an enormous and growing field, summarized in both the "big data" and "complex systems science" literature. The key benefits to sociohydrology are likely to be in the determination of the directionality, delays and strength of the networks of cause and effect between components of a system. The major limitation to these methods, however, is that they tend to be highly data demanding (Shalizi, 2006).

An alternative pathway towards the determination of causality can be drawn from the medical science and economic literature. Although randomized controlled trials (RCTs) form a gold standard for inference in these fields, they are frequently impossible to implement (Stock and Watson, 2010). Econometric methods - a suite of empiricalstatistical techniques to identify causal understanding - are becoming increasingly important as an alternative basis for causal inference (Angrist and Pischke, 2009). These tools of causal inference do not make assumptions about the underlying system microeconomics or dynamics. The main goal of causal inference is to employ an "identification strategy" to approximate an RTC with real-world empirical data. When selection is random (i.e., as in an RCT), the difference in outcomes across treatment groups represents the causal impact of the treatment. This differs from a statistical regression in that selection within a regression is not random, meaning that regressions provide information only about correlations but not causation.

Causal inference employs statistical methods in an attempt to try to obtain "pseudo-randomization" in a dataset in which random selection does not clearly exist. In other 
words, the goal of causal inference is to overcome selection bias (which is present without random sampling) in order to determine the causal effect of the treatment of interest. The core techniques are regression discontinuity designs, instrumental variables methods for the analysis of natural experiments, and differences-in-differences methods that take advantage of changes in policy (Angrist and Pischke, 2009). These statistical tools for causal inference were originally developed to gain intuition in complex socio-economic systems, which share many similarities with sociohydrologic systems. Methods of causal inference are not yet widely used in the sociohydrologic studies represented by the special issue, but could potentially provide a powerful alternative to the data-intensive causality metrics developed in nonlinear science fields.

\subsection{Modeling}

The final methodological area within sociohydrology is mathematical modeling. Mathematical models were proposed for several specific coupled human-water systems in the special issue (see Table 1). Modeling approaches range from "toy" models consisting of a few coupled differential equations to detailed, region-specific models. A broad review of coupled human-environmental models can be found in Letcher et al. (2013).

Existing models used in the special issue, such as the Soil and Water Assessment Tool (SWAT) (Zeng and Cai, 2014; Zhang et al., 2014), land surface hydrologic models (Kummu et al., 2014), or policy models (van Soesbergen and Mulligan, 2014), can be used to provide detailed descriptions of hydrological response to exogenous human drivers. These modeling approaches, while informative, do not clearly depart from the current hydrological paradigm.

In an effort to treat human systems as part of the water cycle, systems dynamics models have been proposed to describe the sociohydrologic system. For example, Srinivasan (2015) developed a model for how water-human systems developed in Chennai, India. Pande et al. (2014) built a theoretical model about how technology and human water demands can evolve in a water-scarce society. Elshafei et al. (2014) developed a conceptual model that accounted for water demands and evolving community awareness of environmental conditions, testing it over two idealized catchments. A dynamical modeling approach allows for full coupling, either directly between the human and water systems, as in water withdrawals, or indirectly. For example, several models conceptualized a dynamic social awareness of the environment (Di Baldassarre et al., 2013b; Elshafei et al., 2014; van Emmerik et al., 2014). The representation of complex aspects of a social system is clearly a major challenge to these models, although empirical observations of the modeled system can incorporate specific details of household behavior, the water distribution system, pricing and their influence on water use (Srinivasan, 2015). These models allow for asking questions about the coupled system's behavior that cannot be asked of historical data, given that a region's history followed one fixed trajectory. For example, Di Baldassarre et al. (2015) explored the effect of choosing infrastructure or adapting to floods on flood damages. As Loucks (2015) points out, "human behavior can be surprising, and we would like to be forewarned about and prepare for such possible surprises."

Understanding sociohydrology through the lens of complex systems suggests an expanded role for modeling in future work. Features such as dynamic connectivity, threshold behavior, and multiple stable states are characteristic of nonlinear systems, and models that can reproduce these behaviors are likely to provide useful insights into potential modes of sociohydrologic behavior. To date, modeling studies tend towards being very specific - and thus hard to generalize beyond a given case study - or very general, and thus dependent upon the construction of "environmental sensitivity" metrics, which are challenging to measure, model or describe in concrete terms. In future studies, the use of data analytics to unravel networks of cause and effect, in conjunction with numerical modeling to explore the potential behaviors that such networks can produce, could provide a robust and generalizable approach to understanding these systems.

\section{Norms and ethics}

Sociohydrology presents many new challenges for hydrologists, one of which is that sociohydrologic research may explicitly explore and influence the lives of people within a studied system. Traditionally, hydrologists have tended to view themselves as impartial observers of the systems they study, avoiding the need to address ethical questions about their role as researchers. In at least some sociohydrologic studies, this position is likely to become untenable. Instead, sociohydrologists may need to confront questions about social norms (collectively held beliefs on how individuals should behave in a particular context), values (benefit derived by an individual from a particular good or service) and their influence on sociohydrologic research (Ertsen et al., 2014; Lane, 2014; Wescoat Jr., 2013). These challenges are most pressing for researchers studying contemporary systems over constrained spatial scales. These researchers are necessarily both participants and observers, because their research could influence decision-making and policy and therefore social futures. The potential for the research outcomes to directly impact people's lives raises a clear ethical dimension to sociohydrology. This dimension is less urgent for researchers studying historical sociohydrologic systems over timescales of hundreds or thousands of years, who can investigate dynamics and feedbacks as impartial observers. Although some would argue that any research reflects the researcher's own values and biases, in this case the researcher's framing arguably has less direct real-world implications. 


\subsection{Researchers as participant observers}

When researchers study contemporary sociohydrologic systems, the issue of norms arises because the research itself could influence real-world outcomes. The choices hydrologists make about what to study and therefore what information to provide decision makers are not "scientific" or objective. This raises two concerns: the framing of research questions, and the validity and legitimacy of the research undertaken.

\subsubsection{Value-laden framing of research questions}

Many studies in the hydrologic literature are motivated by studying water problems faced by society, from floods and drought, to the impacts of climate change, to predicting water resource availability. When sociohydrologists engage in research with the objective of informing decision makers, their research outputs could affect the trajectory of the coupled human-water system. Prediction in hydrologic modeling must be thought through carefully because of "the power that it has to shape the landscape" (Lane, 2014). Despite good intentions, researchers, particularly natural scientists, often do not acknowledge the values implicit in their study design.

This subjectivity raises ethical questions because decisions about what to study are value-laden. This is particularly important when the hydrologist is an outsider to the region of study; there may be a divergence between the hydrologist's own values and those of the majority of the local community at the research site. For instance, some scholars have critiqued western researchers for imposing their views on large dams on the developing world, arguing that it has constrained them from developing their own infrastructure to developed world levels (Muller, 2010). This critique is ongoing: development efforts in Afghanistan after 3 decades of war still focus on large dams, regardless of the practicality of such plans or the existence of the institutional capacity needed to manage the dams (Ahlers et al., 2014).

There is also a tendency to assume that model equations and variables are "scientifically chosen". However, model structure and spatial and temporal scale of variables represent a choice by researchers that may implicitly privilege some water users. For instance, the decision to focus on aggregate measures, such as water resources at the basin scale and availability to a "representative" water user, overlooks the fact that low streamflows in dry years may disproportionally affect poorer, more vulnerable populations. Others may focus on preserving ecological flows and fail to recognize that dry season flows for agriculture are the biggest constraint. Many researchers do not openly acknowledge the implications of the choice of model variables and the value judgments implicit in them.

\subsubsection{Validity and legitimacy of research}

Most hydrologic research is designed to incorporate data and assumptions in forms that scientists recognize - stream gage data, groundwater level data from water level sensors, hydroclimatic data from weather stations, etc. But often sociohydrologic knowledge is distributed and held by people who live within the water system. Scientific studies have no way of incorporating sometimes profound knowledge of the water system that "lay" people have (Lane, 2014). Particularly in data-scarce regions, modelers often prefer to use simplistic assumptions that turn out to be incorrect, rather than risk relying on unconventional sources of information.

To address these concerns, Gober and Wheater (2014) suggest that sociohydrology can play a role in considering community values and local knowledge in scientific studies by eliciting the views of stakeholders. Lane (2014) recommends calling on "non-certified" experts, local resource users who have tremendous understanding of the system who could validate and contribute to such assumptions by arguing that such "co-production" of knowledge between researchers and society could result in more robust hydrologic prediction. Several previous studies have highlighted how such collaborative modeling exercises between stakeholder communities and researchers could be undertaken.

\subsection{Researchers as impartial observers}

When researchers study the historical dynamics of sociohydrologic systems over long timescales of hundred of years (Di Baldassarre et al., 2013a), the assumption of an impartial observer is probably a reasonable one. Here, the research cannot influence the social outcomes observed and so the concerns are more pedantic. Several papers have used stylized or toy models to study the dynamics of sociohydrologic systems. In the majority of these modeling studies, norms are not explicitly discussed; rather they are implicit in model equations and derived from secondary literature. Only a few studies have attempted to empirically investigate social norms using primary data or textual analysis of historical or linguistic records.

\subsubsection{Values as model feedbacks}

In these studies, social norms express how societies adapt themselves to environmental change. Di Baldassarre et al. (2013a) examine sociohydrologic responses to flood over long periods of time. In their sociohydrological model of flooding, social norms are expressed through the "awareness" variable. The memory of devastation gets imprinted in collective social memory and prevents societies from settling close to the river in the aftermath of a flood. As the memory fades, the norms weaken and societies once again settle closer to the river. 
Several studies have highlighted how changing values in favor of the environment have resulted in water being reallocated from human uses to restore ecological flows. In fact, hydrologic flows in these systems could not be predicted without understanding how preferences have changed. Kandasamy et al. (2014) analyze the dynamics of the Murrumbidgee over a 100 -year time period. They find that social values and norms have shifted in favor of preserving the environment. This has resulted in reductions in anthropogenic water abstractions and more water being reallocated to the environment. Liu et al. (2014) report similar dynamics in the Tarim River basin in China, where they refer to changing norms as a balancing or restorative force. Elshafei et al. (2014) propose a general model to capture the dynamics in such systems using a "community sensitivity state variable", which captures the perceived level of threat to a community's quality of life. The community sensitivity variable reflects social norms about the environment; economists and policy researchers have extensive experience in designing research tools, including surveys, which might be suitable to measure social values and norms.

\subsubsection{Values emergent from empirical analysis}

In the papers described above, both social values and norms are deduced from the decisions societies make in response to environmental variables (floods or ecosystem decline). However, the norms and values themselves are not the subject of study. Only a few studies have investigated social norms over water empirically. Wescoat Jr. (2013) examines how norms vary, by examining how the same norm - "duty of water" was applied very differently in colonial India (as a maximum amount of water applicable to a given amount of land) versus the western USA (as the minimum standard for private water rights appropriation and use.) In a contemporary setting, Wutich et al. (2014) examine how both environmental and socio-economic variables influence community perceptions of what types of infrastructure solutions are feasible. The study finds that community norms and therefore how communities invest in infrastructure are shaped by water resource availability. Chang et al. (2014) take an economic approach (hedonic value estimation) using property sales as a proxy to estimate how people value water quality improvements and consequently enforcement of water quality regulations.

The modeling and empirical approaches are somewhat complementary. One potential shortcoming of many of the toy or stylized models is the difficulty in validation of the system dynamics. This difficulty can be bridged by the methods used by these empirical studies to justify or derive model equations and parameters. For instance, the behavior of the "community sensitivity" variable might be verified by analyzing newspaper articles or government documents over time to analyze the frequency and usage of key words.

\section{Discussion and future directions}

The special issue provided an opportunity to reflect on current research in sociohydrology, as well as the state of the field more generally. The papers in the special issue are varied, but they all focus on improving our knowledge of coupled human-water systems to address important societal challenges, a key aspect of sociohydrology. These papers have highlighted some of the important issues that must be explored as the field continues to grow and develop.

In a survey of econometric studies, McDonald (1987) laid out the five steps towards creation of new knowledge: data collection, examination of the data to determine the facts that require explanation, theory and model development to explain the pertinent facts, model calibration and validation, and model application. One could argue that this knowledge creation process is universal across disciplines, and it already occurred in traditional hydrology. Based on the special issue, sociohydrology is currently focused on the first three steps as theories are posed about the coupled behavior of humanwater systems, particularly the feedbacks between the two systems and when these feedbacks occur. For those coming to sociohydrologic research from the hydrology discipline, step 4, model calibration and validation, will be a different process with different standards as compared to traditional hydrologic models (Troy et al., 2015).

Our assessment of the literature highlights two major themes that need to be reconciled by future researchers. The first of these relates to the observation that sociohydrology cannot focus on two-way feedbacks between human and water systems without acknowledging that these feedbacks are embedded in a complex web of cause and effect represented by socio-ecologic systems. This recognition suggests that the modes of interaction between hydrologic variables and social variables will be multifaceted, difficult to isolate, variable from system to system, and nested in terms of both spatial and temporal scales. Thus, definitions of sociohydrology that focus on the clear identification of two-way feedbacks between human and water systems are likely to be challenging to work with in practice, because the identification of such two-way feedbacks is itself a non-trivial problem, and are potentially an inappropriate way to frame the relationship between society and water systems.

The second consequence of recognizing that sociohydrology arises from a complex system is the opportunity to draw on the huge developments in complex-systems science and data analysis. While we have not comprehensively reviewed this field, the range of tools for inferring causality and for reconstructing elements of a nonlinear dynamical system from incomplete observations are highly pertinent to analyzing the behavior of sociohydrologic systems - provided data limitations can be overcome. Alternative interpretations of causality, as embodied by econometric approaches, offer further approaches towards analyzing these systems. These data analysis techniques have not been implemented in sociohydrologic 
studies to date, and they represent a significant opportunity to formalize understanding of the relationship between human activity and hydrologic variability.

While the theme of sociohydrology as a complex systems science identifies opportunities at the cutting edge of quantitative analysis and modeling, the other emergent theme - that of sociohydrologic research as a value-laden, human activity - pulls researchers in the opposite direction. While social scientists routinely address the ethical implications of their work - particularly work that incorporates intervention and experimentation - hydrologists typically lack awareness and a framework for evaluating the ethical consequences of their studies. The human implications of the research choices that hydrologists make may need to be incorporated into the research toolkit of sociohydrologists.

Sociohydrology as a science of people and water has emerged primarily from the hydrological literature. This poses numerous oppositional challenges: the desire to be quantitative but to incorporate (often qualitative and specific) knowledge from social science disciplines; the challenge of reconciling numerical data with descriptive histories; the need to base analyses on empirical facts but to develop generalizable understanding; and the desire to observe and predict the behavior of a system while being a part of that system. As Ertsen et al. (2014) lays out, there are two potential approaches to modeling human agency. One approach is to start at the largest scale possible, society itself, with time steps of years to decades, depending on the timescale of decisions/changes made by society; we can think of this as a top-down approach. The other approach is to start at the level of human beings themselves, with institutions developing in the model through personal relationships of the individual humans; this would be a bottom-up approach. These are choices that are going to be confronted in many sociohydrologic studies, particularly those focused on modeling.

Sociohydrology aims to be a use-inspired science to inform the complex water sustainability challenges faced in the Anthropocene (Sivapalan, 2015; Sivapalan et al., 2014). "Use-inspired" means it may encompass both the fundamental and applied sciences. Quantifying and understanding the feedbacks in sociohydrologic systems, essentially understanding the fundamentals of the systems, is needed before it can be applied for policy making. In addition, simply developing the science is insufficient: how the knowledge is disseminated to policy makers may determine the utility of sociohydrology and its models (Gober and Wheater, 2015). As Sivapalan (2015) points out, the natural sciences and social sciences can mutually benefit from working together on sociohydrologic problems, each with their respective strengths; as Gober and Wheater (2015) discuss, there is a rich literature and a need to include policy makers and policy scientists in sociohydrology.

The breadth, depth and sheer number of papers contributed to the special issue suggest that sociohydrology is vibrant, exciting and relevant to many authors working at the inter- face of hydrology and social systems. While data, methodologies, norms, ethics and the hurdles of interdisciplinarity present non-trivial challenges to achieving the vision of understanding coupled human-water systems, there are also tremendous opportunities to be seized by drawing on socioecologic systems thinking, complex systems science, econometrics, and the detailed disciplinary expertise required to describe these systems in isolation. These opportunities have the potential to greatly increase our understanding of sociohydrologic systems, thereby allowing for better understanding and prediction of water problems.

Acknowledgements. The authors would like to thank Maurits Ertsen, Giuliano Di Baldassarre, and an anonymous reviewer for their thought-provoking and helpful reviews.

Edited by: A. Montanari

\section{References}

Ahlers, R., Brandimarte, L., Kleemans, I., and Sadat, S. H.: Ambitious development on fragile foundations: Criticalities of current large dam construction in Afghanistan, 54, 49-58, doi:10.1016/j.geoforum.2014.03.004, 2014.

Angrist, J. D. and Pischke, J.-S.: Mostly Harmless Econometrics: An Empiricist's Companion, 1st Edn., Princeton University Press, Princeton, NJ, 2009.

Brádzil, R. and Kundzewicz, Z. W.: Historical hydrology - Editorial, Hydrolog. Sci. J., 51, 733-738, doi:10.1623/hysj.51.5.733, 2006.

Brádzil, R., Kundzewicz, Z. W., and Benito, G.: Historical hydrology for studying flood risk in Europe, Hydrolog. Sci. J., 51, 739764, doi:10.1623/hysj.51.5.739, 2006.

Brázdil, R., Chromá, K., Valášek, H., and Dolák, L.: Hydrometeorological extremes derived from taxation records for south-eastern Moravia, Czech Republic, 1751-1900 AD, Clim. Past, 8, 467481, doi:10.5194/cp-8-467-2012, 2012.

Buckley, B. M., Anchukaitis, K. J., Penny, D., Fletcher, R., Cook, E. R., Sano, M., Nam, L. C., Wichienkeeo, A., Minh, T. T., and Hong, T. M.: Climate as a contributing factor in the demise of Angkor, Cambodia, P. Natl. Acad. Sci. USA, 107, 6748-6752, doi:10.1073/pnas.0910827107, 2010.

Chang, H., Thiers, P., Netusil, N. R., Yeakley, J. A., RollwagenBollens, G., Bollens, S. M., and Singh, S.: Relationships between environmental governance and water quality in a growing metropolitan area of the Pacific Northwest, USA, Hydrol. Earth Syst. Sci., 18, 1383-1395, doi:10.5194/hess-18-13832014, 2014.

Cumming, G. S., Cumming, D. H., and Redman, C. L.: Scale mismatches in social-ecological systems: causes, consequences, and solutions, Ecol. Soc., 11, 14, 2006.

Das, G., Lin, K. I., Mannila, H., Renganathan, G., and Smyth, P.: Rule Discovery from Time Series, AAAI Press, 16-22, 1998.

Dermody, B. J., van Beek, R. P. H., Meeks, E., Klein Goldewijk, K., Scheidel, W., van der Velde, Y., Bierkens, M. F. P., Wassen, M. J., and Dekker, S. C.: A virtual water network of the Roman world, 
Hydrol. Earth Syst. Sci., 18, 5025-5040, doi:10.5194/hess-185025-2014, 2014.

Di Baldassarre, G., Kooy, M., Kemerink, J. S., and Brandimarte, L.: Towards understanding the dynamic behaviour of floodplains as human-water systems, Hydrol. Earth Syst. Sci., 17, 3235-3244, doi:10.5194/hess-17-3235-2013, 2013a.

Di Baldassarre, G., Viglione, A., Carr, G., Kuil, L., Salinas, J. L., and Blöschl, G.: Socio-hydrology: conceptualising humanflood interactions, Hydrol. Earth Syst. Sci., 17, 3295-3303, doi:10.5194/hess-17-3295-2013, 2013b.

Di Baldassarre, G., Viglione, A., Carr, G., Kuil, L., Yan, K., Brandimarte, L., and Blöschl, G.: Debates-Perspectives on socio-hydrology: Capturing feedbacks between physical and social processes, Water Resour. Res., 51, 4770-4781, doi:10.1002/2014WR016416, 2015.

Elshafei, Y., Sivapalan, M., Tonts, M., and Hipsey, M. R.: A prototype framework for models of socio-hydrology: identification of key feedback loops and parameterisation approach, Hydrol. Earth Syst. Sci., 18, 2141-2166, doi:10.5194/hess-18-21412014, 2014.

Ertsen, M. W., Murphy, J. T., Purdue, L. E., and Zhu, T.: A journey of a thousand miles begins with one small step - human agency, hydrological processes and time in socio-hydrology, Hydrol. Earth Syst. Sci., 18, 1369-1382, doi:10.5194/hess-18-13692014, 2014.

Falkenmark, M. and Chapman, T.: Comparative hydrology: an ecological approach to land and water resources, The UNESCO Press, Paris, 1989.

Fernald, A., Guldan, S., Boykin, K., Cibils, A., Gonzales, M., Hurd, B., Lopez, S., Ochoa, C., Ortiz, M., Rivera, J., Rodriguez, S., and Steele, C.: Linked hydrologic and social systems that support resilience of traditional irrigation communities, Hydrol. Earth Syst. Sci., 19, 293-307, doi:10.5194/hess-19-293-2015, 2015.

French, K., Duffy, C., and Bhatt, G.: The hydroarchaeological method: A case study at the Maya site of Palenque, Lat. Am. Antiq., 2012.

Gober, P. and Wheater, H. S.: Socio-hydrology and the sciencepolicy interface: a case study of the Saskatchewan River basin, Hydrol. Earth Syst. Sci., 18, 1413-1422, doi:10.5194/hess-181413-2014, 2014.

Gober, P. and Wheater, H. S.: Debates-Perspectives on sociohydrology: Modeling flood risk as a public policy problem, Water Resour. Res., 51, 4782-4788, doi:10.1002/2015WR016945, 2015.

Gupta, H. V., Perrin, C., Blöschl, G., Montanari, A., Kumar, R., Clark, M., and Andréassian, V.: Large-sample hydrology: a need to balance depth with breadth, Hydrol. Earth Syst. Sci., 18, 463477, doi:10.5194/hess-18-463-2014, 2014.

Kandasamy, J., Sounthararajah, D., Sivabalan, P., Chanan, A., Vigneswaran, S., and Sivapalan, M.: Socio-hydrologic drivers of the pendulum swing between agricultural development and environmental health: a case study from Murrumbidgee River basin, Australia, Hydrol. Earth Syst. Sci., 18, 1027-1041, doi:10.5194/hess-18-1027-2014, 2014.

Konar, M., Hussein, Z., Hanasaki, N., Mauzerall, D. L., and Rodriguez-Iturbe, I.: Virtual water trade flows and savings under climate change, Hydrol. Earth Syst. Sci., 17, 3219-3234, doi:10.5194/hess-17-3219-2013, 2013.
Kumar, P.: Typology of hydrologic predictability, Water Resour. Res., 47, W00H05, doi:10.1029/2010WR009769, 2011.

Kummu, M., Gerten, D., Heinke, J., Konzmann, M., and Varis, O.: Climate-driven interannual variability of water scarcity in food production potential: a global analysis, Hydrol. Earth Syst. Sci., 18, 447-461, doi:10.5194/hess-18-447-2014, 2014.

Lane, S. N.: Acting, predicting and intervening in a sociohydrological world, Hydrol. Earth Syst. Sci., 18, 927-952, doi:10.5194/hess-18-927-2014, 2014.

Letcher, R. A. K., Jakeman, A. J., Barreteau, O., Borsuk, M. E., ElSawah, S., Hamilton, S. H., Henriksen, H. J., Kuikka, S., Maier, H. R., Rizzoli, A. E., van Delden, H., and Voinov, A. A.: Selecting among five common modelling approaches for integrated environmental assessment and management, Environ. Modell. Softw., 47, 159-181, doi:10.1016/j.envsoft.2013.05.005, 2013.

Levin, S. A.: Ecosystems and the biosphere as complex adaptive systems, Ecosystems, 1, 431-436, 1998.

Liu, J., Dietz, T., Carpenter, S. R., Alberti, M., Folke, C., Moran, E., Pell, A. N., Deadman, P., Kratz, T., Lubchenco, J., Ostrom, E., Ouyang, Z., Provencher, W., Redman, C. L., Schneider, S. H., and Taylor, W. W.: Complexity of Coupled Human and Natural Systems, Science, 317, 1513-1516, doi:10.1126/science.1144004, 2007.

Liu, Y., Tian, F., Hu, H., and Sivapalan, M.: Socio-hydrologic perspectives of the co-evolution of humans and water in the Tarim River basin, Western China: the Taiji-Tire model, Hydrol. Earth Syst. Sci., 18, 1289-1303, doi:10.5194/hess-18-12892014, 2014.

Loucks, D. P.: Debates-Perspectives on socio-hydrology: Simulating hydrologic-human interactions, Water Resour. Res., 51, 4789-4794, doi:10.1002/2015WR017002, 2015.

McDonald, J. F.: Econometric Studies of Urban Population Density: A Survey, J. Urban Econ., 26, 361-385, 1987.

Micklin, P.: The Aral Sea Disaster, Annu. Rev. Earth Pl. Sc., 35, 47-72, doi:10.1146/annurev.earth.35.031306.140120, 2007.

Muller, M.: Fit for purpose: taking integrated water resource management back to basics, Irrig. Drainage Syst., 24, 161-175, doi:10.1007/s10795-010-9105-7, 2010.

Muñoz-Villers, L. E. and McDonnell, J. J.: Land use change effects on runoff generation in a humid tropical montane cloud forest region, Hydrol. Earth Syst. Sci., 17, 3543-3560, doi:10.5194/hess17-3543-2013, 2013.

O’Bannon, C., Carr, J., Seekell, D. A., and D'Odorico, P.: Globalization of agricultural pollution due to international trade, Hydrol. Earth Syst. Sci., 18, 503-510, doi:10.5194/hess-18-5032014, 2014.

O'Connell, P. E. and O'Donnell, G.: Towards modelling flood protection investment as a coupled human and natural system, Hydrol. Earth Syst. Sci., 18, 155-171, doi:10.5194/hess-18-1552014, 2014.

Ostrom, E.: A General Framework for Analyzing Sustainability of Social-Ecological Systems, Science, 325, 419-422, doi:10.1126/science.1172133, 2009.

Pande, S. and Ertsen, M.: Endogenous change: on cooperation and water availability in two ancient societies, Hydrol. Earth Syst. Sci., 18, 1745-1760, doi:10.5194/hess-18-1745-2014, 2014.

Pande, S., Ertsen, M., and Sivapalan, M.: Endogenous technological and population change under increasing water scarcity, Hy- 
drol. Earth Syst. Sci., 18, 3239-3258, doi:10.5194/hess-18-32392014, 2014.

Parker, G.: Crisis and catastrophe: The global crisis of the seventeenth century reconsidered, Am. Hist. Rev., 113, 1053-1079, 2008.

Ribeiro Neto, A., Scott, C. A., Lima, E. A., Montenegro, S. M. G. L., and Cirilo, J. A.: Infrastructure sufficiency in meeting water demand under climate-induced socio-hydrological transition in the urbanizing Capibaribe River basin - Brazil, Hydrol. Earth Syst. Sci., 18, 3449-3459, doi:10.5194/hess-18-34492014, 2014.

Scott, C. A., Vicuña, S., Blanco-Gutiérrez, I., Meza, F., and VarelaOrtega, C.: Irrigation efficiency and water-policy implications for river basin resilience, Hydrol. Earth Syst. Sci., 18, 1339-1348, doi:10.5194/hess-18-1339-2014, 2014.

Shalizi, C. R.: Methods and Techniques of Complex Systems Science: An Overview, in: Complex systems science in biomedicine, edited by: Deisboeck, T. S. and Kresh, J. Y., Springer, New York, 2006.

Sivapalan, M.: Debates-Perspectives on socio-hydrology: Changing water systems and the "tyranny of small problems" Socio-hydrology, Water Resour. Res., 51, 4795-4805, doi:10.1002/2015WR017080, 2015.

Sivapalan, M., Savenije, H. H. G., and Blöschl, G.: Sociohydrology: A new science of people and water, Hydrol. Process., 26, 1270-1276, doi:10.1002/hyp.8426, 2012.

Sivapalan, M., Konar, M., Srinivasan, V., Chhatre, A., Wutich, A., Scott, C. A., Wescoat, J. L., and RodriguezIturbe, I.: Socio-hydrology: Use-inspired water sustainability science for the Anthropocene, Earth's Future, 2, 225-230, doi:10.1002/2013EF000164, 2014.

Solé, R. V. and Bascompte, J.: Self-Organization in Complex Systems, Princeton University Press, Princeton, NJ, 2006.

Srinivasan, V.: Reimagining the past - use of counterfactual trajectories in socio-hydrological modelling: the case of Chennai, India, Hydrol. Earth Syst. Sci., 19, 785-801, doi:10.5194/hess19-785-2015, 2015.

Stock, J. H. and Watson, M. W.: Introduction to Econometrics, 3rd Edn., Addison-Wesley, Boston, MA, 2010.

Thompson, S. E., Sivapalan, M., Harman, C. J., Srinivasan, V., Hipsey, M. R., Reed, P., Montanari, A., and Blöschl, G.: Developing predictive insight into changing water systems: useinspired hydrologic science for the Anthropocene, Hydrol. Earth Syst. Sci., 17, 5013-5039, doi:10.5194/hess-17-50132013, 2013.
Troy, T. J., Pavao-Zuckerman, M., and Evans, T. P.: DebatesPerspectives on socio-hydrology: Socio-hydrologic modeling: Tradeoffs, hypothesis testing, and validation, Water Resour. Res., 51, 4806-4814, doi:10.1002/2015WR017046, 2015.

van Emmerik, T. H. M., Li, Z., Sivapalan, M., Pande, S., Kandasamy, J., Savenije, H. H. G., Chanan, A., and Vigneswaran, S.: Socio-hydrologic modeling to understand and mediate the competition for water between agriculture development and environmental health: Murrumbidgee River basin, Australia, Hydrol. Earth Syst. Sci., 18, 4239-4259, doi:10.5194/hess-18-42392014, 2014.

van Soesbergen, A. J. J. and Mulligan, M.: Modelling multiple threats to water security in the Peruvian Amazon using the WaterWorld policy support system, Earth Syst. Dynam., 5, 55-65, doi:10.5194/esd-5-55-2014, 2014.

Wescoat Jr., J. L.: Reconstructing the duty of water: a study of emergent norms in socio-hydrology, Hydrol. Earth Syst. Sci., 17, 4759-4768, doi:10.5194/hess-17-4759-2013, 2013.

Wutich, A., White, A. C., White, D. D., Larson, K. L., Brewis, A., and Roberts, C.: Hard paths, soft paths or no paths? Crosscultural perceptions of water solutions, Hydrol. Earth Syst. Sci., 18, 109-120, doi:10.5194/hess-18-109-2014, 2014.

Yaeger, M. A., Sivapalan, M., McIsaac, G. F., and Cai, X.: Comparative analysis of hydrologic signatures in two agricultural watersheds in east-central Illinois: legacies of the past to inform the future, Hydrol. Earth Syst. Sci., 17, 4607-4623, doi:10.5194/hess17-4607-2013, 2013.

Yoshikawa, S., Yanagawa, A., Iwasaki, Y., Sui, P., Koirala, S., Hirano, K., Khajuria, A., Mahendran, R., Hirabayashi, Y., Yoshimura, C., and Kanae, S.: Illustrating a new global-scale approach to estimating potential reduction in fish species richness due to flow alteration, Hydrol. Earth Syst. Sci., 18, 621-630, doi:10.5194/hess-18-621-2014, 2014.

Zeng, R. and Cai, X.: Analyzing streamflow changes: irrigationenhanced interaction between aquifer and streamflow in the Republican River basin, Hydrol. Earth Syst. Sci., 18, 493-502, doi:10.5194/hess-18-493-2014, 2014.

Zhang, Z., Hu, H., Tian, F., Yao, X., and Sivapalan, M.: Groundwater dynamics under water-saving irrigation and implications for sustainable water management in an oasis: Tarim River basin of western China, Hydrol. Earth Syst. Sci., 18, 3951-3967, doi:10.5194/hess-18-3951-2014, 2014.

Zlinszky, A. and Timár, G.: Historic maps as a data source for socio-hydrology: a case study of the Lake Balaton wetland system, Hungary, Hydrol. Earth Syst. Sci., 17, 4589-4606, doi:10.5194/hess-17-4589-2013, 2013. 